\title{
GENERATION OF REACTIVE OXYGEN SPECIES IN RAT EPIDIDYMAL SPERMATOZOA AFTER CYCLOPHOSPHAMIDE TREATMENT
}

\author{
KASHMIRI ZN ${ }^{1 *}$, SASTRY MS ${ }^{2}$ \\ ${ }^{1}$ Department of Zoology, Dada Ramchand Bakhru Sindhu Mahavidyalaya, Nagpur, Maharashtra, India. ${ }^{2}$ Department of Zoology, Rashtrasant \\ Tukadoji Maharaj Nagpur University, Nagpur, Maharashtra, India. Email: kashmiri_zeenat@yahoo.com
}

Received: 11 January 2018, Revised and Accepted: 05 March 2018

\section{ABSTRACT}

Objective: The aim of this study was to examine the effect of an anticancer drug cyclophosphamide (CPA) on generation of reactive oxygen species (ROS) in epididymal spermatozoa of Wistar rat, Rattus norvegicus.

Methods: For this purpose, the rats were injected intraperitoneally with different doses of CPA (5 mg, $15 \mathrm{mg}$, and $20 \mathrm{mg} / \mathrm{Kg}$ BW for 2 weeks).

Results: Treatment resulted into significantly increased level of ROS in CPA-treated groups when compared to the vehicle-treated control group.

Conclusion: The results revealed that CPA has deleterious effect on the sperm morphology and physiology, which is dose and duration dependent and at certain doses cause the production of a number of reactive molecules and free radicals derived from molecular oxygen consequently resulting into adverse effect on the sperm function and hence on reproduction.

Key words: Reactive oxygen species, Free radical, Cyclophosphamide, Spermatozoa.

(c) 2018 The Authors. Published by Innovare Academic Sciences Pvt Ltd. This is an open access article under the CC BY license (http://creativecommons. org/licenses/by/4. 0/) DOI: http://dx.doi.org/10.22159/ajpcr.2018.v11i4.24826

\section{INTRODUCTION}

Reactive oxygen species (ROS) is a phrase used to describe a number of reactive molecules and free radicals derived from molecular oxygen or highly reactive oxidizing agents belonging to the class of free radicals [1-3]. Epididymal sperm maturation is considered as an essential process. Several modifications occur during transformation of immature testicular spermatozoa to mature epididymal gametes capable of fertilization. One of the modifications is changes in their capacity for ROS generation and tyrosine phosphorylation that are thought to be related to the ability of the spermatozoa to engage in the process of sperm capacitation [4-6]. ROS plays a significant role in sperm physiology. Production of ROS by spermatozoa has been associated with the loss of sperm motility, sperm hyperactivation, decreased capacity for sperm-oocyte fusion, and loss of fertility.

ROS such as the superoxide anion, hydrogen peroxide, and nitric oxide at low-level facilitate hyperactivation, capacitation, acrosome reaction, motility, fertilization, and oocyte adhesion of spermatozoa [7], but higher ROS damages a variety of biomolecules such as lipids, amino acids, carbohydrates, proteins, DNA, and adversely affect the sperm function $[8,9]$.

Anticancer drug cyclophosphamide (CPA) belonging to the class of oxazaphosphorines is a bioactivated metabolite and alkylating agent that show cytostatic effects by forming covalent DNA adducts. Treatment with cytotoxic chemotherapy is associated with significant reproductive damage, and alkylating agents are the most common agent implicated in the development of infertility $[10,11]$.

To prove the development of infertility due to anticancer drug CPA, the present study was conducted by generation of ROS in rat epididymal spermatozoa.

\section{METHODS}

\section{Chemicals}

The anticancer drug CPA (Endoxan-N, CAS no. 50-18-0), with the chemical formula $\mathrm{C}_{7} \mathrm{H}_{15} \mathrm{Cl}_{2} \mathrm{~N}_{2} \mathrm{O}_{2} \mathrm{P}$ and molecular weight, $261.086 \mathrm{~g} / \mathrm{mol}$, manufactured by Cadila Healthcare Limited, Goa. All other reagents were obtained from Sigma Chemical Company.

\section{Experimental animals}

Wistar albino rats (Rattus norvegicus) with average body weight of 250- 300 g obtained from the Department of Biochemistry, R. T. M. Nagpur University, Nagpur, were used for the study. Animals were housed in polypropylene box type cages, bedded with rice husk under controlled environmental condition and humidity controlled with free access to food and water. All experimental procedures were carried out under strict compliance with the Institutional Animal Ethical Committee according to the guidelines of the Committee for the Purpose of Control and Supervision of Experimental Animals.

\section{Treatments}

Animals were allowed to acclimatize for a period of week before being treated. They were selected randomly and divided into two groups with six animals in each group, vehicle-treated control group and experimental group. The experimental group animals were administered with $5 \mathrm{mg}, 15 \mathrm{mg}$, and $20 \mathrm{mg} / \mathrm{Kg} \mathrm{BW} /$ day of CPA for 2 weeks intraperitoneally and the vehicle-treated group with equal volume of saline.

\section{Spermatozoa sample preparation for ROS}

The animals were sacrificed $24 \mathrm{~h}$ after the last day of each experiment. The cauda epididymis was removed, cleared of fat and connective tissue, rinsed in Dulbecco's phosphate-buffered saline (PBS) solution, and cut into pieces. The initial characteristics such as sperm count and motility were recorded. Each piece of tissue was transferred to small Petri dishes, containing 3ml of Dulbecco's PBS solution prewarmed to $37^{\circ} \mathrm{C}$. The epididymis was incubated for $10 \mathrm{~min}$ to allow diffusion of the spermatozoa. The remaining tissues were then removed, and the cells were counted and adjusted to $10 \times 10^{6}$ spermatozoa $/ \mathrm{ml}$.

Estimation of ROS by chemiluminescence assay

ROS levels of rat spermatozoa were measured using luminol-peroxidasedependent chemiluminescence assay [12]. In this method, Luminol 
(5-amino-2,3-dihydro-1,4-phthalazinedione) is used as a probe to assess ROS generation by spermatozoa. Chemiluminescence occurs when excited electrons return to ground state. With this protocol, sample was centrifuged at $300 \mathrm{rpm}$ for $5 \mathrm{~min}$, and after washing the pellet with PBS it was resuspended in the same washing media at a concentration of $10 \times 10^{6}$ sperm per ml. $4 \mu \mathrm{L}$ of luminol (5-amino-2,3-dihydro-1,4phthalazinedione) prepared as $5 \mathrm{~mm}$ stock in dimethyl sulfoxide, was added to the mixture and served as a probe. The luminol-dependent chemiluminescence was enhanced by the addition of horseradish peroxidase. Chemiluminescence is measured in the integration mode using a luminometer (Luminoskan Ascent - Thermo Scientific) at $37^{\circ} \mathrm{C}$ for $2 \mathrm{~min}$ after the luminol was added. ROS production was expressed as counted photons per minute $(\mathrm{cpm}) / 10 \times 10^{6}$ spermatozoa.

\section{Statistical analysis}

The data were analyzed statistically following the method adopted by Delgaard [13]. Standard deviation and probability test, i.e., t-test were employed to know the levels of significance. A statistical significance level of $\mathrm{p}<0.05$ was accepted.

\section{RESULTS}

Measurement of ROS generation in epididymal spermatozoa was undertaken using chemiluminescence. The spontaneous ROS generation exhibited by CPA-treated groups ( $5 \mathrm{mg}, 15 \mathrm{mg}$, and $20 \mathrm{mg} / \mathrm{Kg}$ BW for 2 weeks) was significantly greater than the level shown by the vehicletreated control group (Fig. 1).

\section{DISCUSSION}

ROS measurement appears to be a helpful tool in the initial evaluation and follow-up of infertile male patients because high oxidative stress seems to be strongly correlated with low fertility [14]. Adequate amount of ROS is required to acquire fertilizing capacities in male, but higher ROS level damages a variety of biomolecules such as lipids, amino acids, carbohydrates, proteins, and DNA and causes apoptosis in sperm, also adversely affect the sperm function leading to infertility in men $[15,16]$.

The present study demonstrated the adverse effect of CPA on testicular gametogenic and androgenic activities. A significant difference in the level of ROS between the vehicle-treated control and rats treated with CPA was also described by Venkatesh et al. [17]. In addition, ROS may also affect the sperm axoneme by affecting microtubules assembly, inhibits mitochondrial function and affects the synthesis of DNA, RNA, and proteins [18], decreased axonemal protein phosphorylation, sperm immobilization (as in the present study dose $20 \mathrm{mg} / \mathrm{Kg}$ BW CPA), by the inhibition of glucose-6phosphate dehydrogenase [19]. Moreover, ROS has also been implicated to cause mutation or polymorphism in both nuclear and mitochondrial DNA of spermatozoa [14]. Our results are also in consonance with the previous workers on CPA-induced testicular toxicity [20-24].

The administration of CPA may have resulted into electron leakage from defective sperm mitochondria at complexes I and II, and hence, could

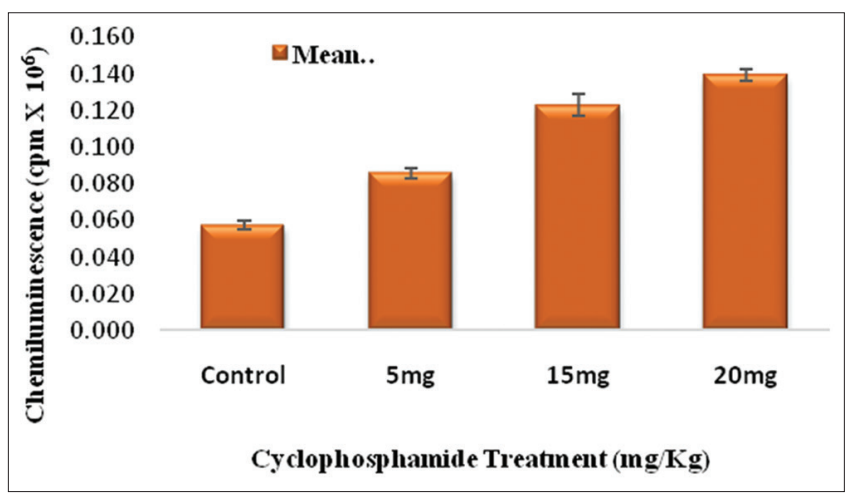

Fig. 1: Spontaneous generation of chemiluminescence by rat spermatozoa following cyclophosphamide treatment be another potential source of oxygen radicals as described by Vernet et al. Baker and Aitken [12,25]. Our results are also in consonance with Anderson et al. [26] after the administration of estrogenic compounds in human spermatozoa, nickel-induced oxidative stress in testis of mice [27] after the effect of nitric oxide on human spermatozoa activity [28], or during infertility $[17,29]$ or infiltration of leukocytes [30,31], during infections in the male genital tract, or in a condition of varicocele [32], or in patients with spinal cord injury [33] or chronic prostatitis [34], urogenital inflammation [35], or by shortterm exposure to organic hydroperoxides in vivo in rat model since elevated levels of ROS can induce oxidative damage to DNA which is of potential risk to reproduction [36], ascorbic deficiency, and smoking may result into male reproductive dysfunctions [37] or tertiary butyl hydroperoxide [38], cryptorchidism [39], hypogonadism [40] or genetic nuclear, and mitochondrial [41].

\section{CONCLUSION}

Ourresults demonstratethattheluminol-dependent chemiluminescence assay for ROS measurement is both accurate and reliable, and easy and rapid. Moreover, the obtained results also emphasizes that CPA has deleterious effect on the sperm morphology as observed in the sperm analysis [42] and physiology, which is dose and duration dependent and at certain doses cause the production of a number of reactive molecules and free radicals derived from molecular oxygen consequently resulting into adverse effect on the sperm function and hence on reproduction.

\section{AUTHOR'S CONTRIBUTIONS}

Both the authors contributed to the study design, manuscript preparation, and critical revision of the manuscript and finalization of the manuscript. ZK responsible for laboratory experiments, data collection, and analysis. Both the authors agree with the content of the manuscript.

\section{CONFLICT OF INTEREST}

There is no conflict of interests.

\section{REFERENCES}

1. Turrens JF. Mitochondrial formation of reactive oxygen species. J Physiol 2003;552:335-44.

2. Held P. An Introduction to Reactive Oxygen Species Measurement of ROS in Cells, Bio Tek Instrument, Inc.; 2015. Available from: http:// www.biotek.com.

3. Dontha SA. Review on antioxidant methods. Asian J Pharm Clin Res 2016;Suppl 1:14-32.

4. Baumber J, Sabeur K, Vo A, Ball BA. Reactive oxygen species promote tyrosine phosphorylation and capacitation in equine spermatozoa. Theriogenology 2003;60:1239-47.

5. Aggarwal D, Sharma M, Singla SK. The role of natural antioxidants as potential therapeutic agent in nephrolithiasis. Asian J Pharm Clin Res 2013; Suppl 1:48-53.

6. O'Flaherty C. Redox regulation of mammalian sperm capacitation. Asian J Androl 2015;17:583-90.

7. de Lamirande E, O'Flaherty C. Sperm activation: Role of reactive oxygen species and kinases. Biochem Biophys Acta 2008;1784:106-15.

8. Agarwal A, Makker K, Sharma R. Clinical relevance of oxidative stress in male factor infertility: An update. Am J Reprod Immuno 2008;159:2- 11

9. Agarwal A, Mulgund A, Alshahrani S, Assidi M, Abuzenadah AM, Sharma $\mathrm{R}$, et al. Reactive oxygen species and sperm DNA damage in infertile men presenting with low level leukocytospermia. Reprod Biol Endocrinol 2014a; $12: 126$.

10. Vaisheva F, Delbes G, Hales BF, Robaire B. Effect of chemotherapeutic agents for non-hodgkin lymphoma, cyclophosphamide, doxorubicin, vincristine, and prednisone (CHOP), on the male rat reproductive system and progeny outcome. J Androl 2007;28:578-87.

11. Kanth A, Kaur P, Ahmed B, Sharma S. Histological effect of anticancer drug cyclophosphamide (CPA) on testis of rattusrattus. Indo American J Pharma Res 2014;4:2645-9.

12. Vernet P, Fulton N, Wallace C, Aitken RJ. Analysis of reactive oxygen species generating systems in rat epididymal spermatozoa. Biol Reprod 
2001;65:1102-13.

13. Delgaard P. Introductory Statistics with R. $2^{\text {nd }}$ ed. New York: Springer Verlag; 2008.

14. Sharma RK, Said T, Agarwal A. Sperm DNA damage and its clinical relevance in assessing reproductive outcome. Asian J Androl 2004; 6:139-48.

15. Agarwal A, Virk G, Ong C, du Plessis S. Effect of oxidative stress on male reproduction. World J Mens Health 2014b;32:1-17.

16. Kashmiri ZN. Reactive oxygen species and fertility in male. World J Pharm Pharm Sci 2015;4:288-98.

17. Venkatesh S, Deecaraman M, Kumar R, Shamsi MB, Dada R. Rate of reactive oxygen species in the pathogenesis of mitochondrial DNA (mtDNA) mutations in male infertility. Ind J Med Res 2009; 129:127- 37.

18. de Lamirande E, Gagnon C. Reactive oxygen species and human spermatozoa. II. Depletion of adenosine triphosphate plays an important role in the inhibition of sperm motility. J Androl 1992;13:379-86.

19. Maneesh M, Jayalekshmi H. Role of reactive oxygen species and antioxidants on pathophysiology of male reproduction. Ind $\mathrm{J}$ Clin Biochem 2006;21:80-9.

20. Das UB, Mallick M, Debnath JM, Ghosh D. Protective effect of ascorbic acid on cyclophosphamide-induced testicular gametogenic and androgenic disorders in male rats. Asian J Androl 2002;4:201-7.

21. Selvakumar E, Prahalathan C, Sudharsan T, Varalakshmi P. Protective effect of lipoic acid on cyclophosphamide-induced testicular toxicity. Clin Chim Acta 2006;367:114-9.

22. Tripathi DN, Jena GB. Astaxanthin inhibits cytotoxic and genotoxic effects of cyclophosphamide in mice germ cells. Toxicology 2008; 248:96-103.

23. Rezvanfar M, Sadrkhanlou R, Ahmadi A, Shojaei-Sadee H, Rezvanfar M, Mohammadirad A, et al. Protection of cyclophosphamideinduced toxicity in reproductive tract histology, sperm characteristics, and DNA damage by an herbal source; evidence for role of free-radical toxic stress. Hum Exp Toxicol 2008;27:901-10.

24. Caribași AO, Türk G, Sönmez M, Sakin F, Ateșșahin A. Toxic effect of Cyclophosphamide on sperm morphology, testicular histology and blood oxidant-antioxidant balance and protective roles of lycopene and ellagic acid. Basic Clin Pharmacol Toxicol 2010;107:730-6.

25. Baker MA, Aitken RJ. Reactive oxygen species in spermatozoa: Methods for monitoring and significance for the origins of genetic disease and infertility. Reprod Biol Endocrinol 2005;3:67.

26. Anderson D, Schmid TE, Baumgartner A, Cemeli-Carratala E, Brinkworth MH, Wood JM. Oestrogenic compounds and oxidativestress (in human sperm and lymphocytes in the cometassay. Mutat Res 2003;544:173-8

27. Doreswamy K, Shrilatha B, Rajeshkumar T, Muralidhara. Nickelinduced oxidative stress in testis of mice: Evidence of DNA damage and genotoxic effects. J Androl 2004;25:996-1003.

28. Wu TP, Huang BM, Tsai HC, Lui MC, Liu MY. Effects of nitric oxide on human spermatozoa activity, fertilization and mouse embryonic development. Arch Androl 2004;50:173-9.

29. Desai N, Sharma R, Makker K, Sabanegh E, Agarwal A. Physiologic and pathologic levels of reactive oxygen species in neat semen of infertile men. Fertil Steril 2009;92:1626-31

30. Pasqualotto FF, Sharma RK, Nelson DR, Thomas AJ, Agarwal A. Relationship between oxidative stress, semen characteristics, and clinical diagnosis in men undergoing infertility investigation. Fertil Steril 2000;73:459-64.

31. Athayde KS, Cocuzza M, Agarwal A, Krajcir N, Lucon AM, Srougi M, et al. Development of normal reference values for seminal reactive oxygen species and their correlation with leukocytes and semen parameters in a fertile population. J Androl 2007;28:613-20.

32. Dada R, Kumar R, Shamsi MB, Sidhu T, Mitra A, Singh S, et al. Azoospermia factor deletions in varicocele cases with severe oligozoospermia. Ind J Med Sci 2007;61:505-10.

33. Padron OF, Brackett NL, Sharma RK, Lynne CM, Thomas AJ Jr., Agarwal A, et al. Seminal reactive oxygen species and sperm motility and morphology in men with spinal cord injury. Fertil Steril 1997;67:1115-20.

34. Henkel R, Ludwig M, Schuppe HC, Diemer T, Schill WB, Weldner W. Chronic pelvic pain syndrome/chronic prostatitis after the acrosome reaction in human spermatozoa. World J Urol 2006;24:39-44.

35. Henkel R, Maass G, Hajimohammad M, Menkveld R, Stalf T, Villegas J, et al. Urogenital inflammation: Changes of leucocytes and ROS. Andrologia 2003;35:309-13.

36. Kumar TR, Muralidhara. Induction of oxidative stress by organic hydroperoxides in testis and epididymal sperm of rats in vivo. J Androl 2007;28:77-85.

37. Esteves SC. Effect of cigarette smoking on levels of seminal oxidative stress in infertile men: A prospective study. Int Braz J Urol 2002; 28:484-5.

38. Kaur F, Sangha GK, Bilaspuri GS. Cyclophosphamide-induced structural and biochemical changes in testis and epididymids of rats. Ind J Exp Biol 1997;35:771-5.

39. Dada R, Gupta NP, Kucheria K. AZF microdeletions associated with idiopathic and non-idiopathic cases with cryptorchidism and varicocele. Asian J Androl 2002;4:259-63.

40. Isidori AM, Giannetta E, Lenzi A. Male hypogonadism. Pituitary 2008; $11: 171-80$

41. Aitken RJ, Curry BJ. Redox regulation of human sperm function: From the physiological control of sperm capacitation to the etiology of infertility and DNA damage in the germ line. Antioxid Redox Signal $2011 ; 14: 367-8$

42. Kashmiri ZN. Toxic Study of an Alkylating agent Cyclophosphamide on the Reproductive System of Male Wistar rat Rattus norvegicus, $\mathrm{Ph}$. D. Thesis Awarded by R.T.M. Nagpur University, Nagpur; 2014. p. $146-50$. 